\title{
Editorial
}

Rev Estomatol Herediana. 2018 Oct-Dic;28(4):221-2

DOI: https://doi.org/10.20453/reh.v28i4.3424

\section{Semblanza al Dr. Freddie Eduardo Williams Díaz}

\section{Semblance to Dr. Freddie Eduardo Williams Díaz}

Nació en la Provincia Constitucional del Callao, el 18 de febrero de 1948, sus padres fueron: Ricardo Williams Cortez y Lucila Díaz de Williams. Realizó sus estudios primarios y secundarios en el Colegio George Washington del Callao, terminando el año 1963 a la edad de 15 años como primer alumno de su clase.

En 1964 ingreso a la Facultad de Ingeniería civil de la Universidad Nacional de Ingeniería estudiando durante 6 meses y donde descubre que no es su vocación y decide prepararse en una academia en el área de ciencias, es así que sus amigos le convencen para viajar a la ciudad de Ica y postular a la Universidad Nacional San Luis Gonzaga, ingresando a la carrera de Odontología en 1965 donde estudió por el lapso de un año y realiza su traslado a la Decana de América: Universidad Mayor de San Marcos donde conoce a sus amistades que perduran hasta la actualidad, egresando el año 1969 a la edad de 21 años siendo el primer puesto de su promoción.

En los años que conozco al Dr. Williams sé que es muy apasionado, perseverante y competitivo en lo que hace, una de sus pasiones es la música que desde pequeño la práctica siendo la batería el instrumento que lo cautivo trayéndole muchos inconvenientes en casa ya que rompía los platos porque practicaba con ellos, es así que en el cuarto año de secundaria forman un grupo de rock con sus compañeros y es por intermedio de la música que conoce a su compañera de vida en 1967, María Antonieta Albites ya que ambos participaban en el coro de la Asociación de Artistas Aficionados, entablándose una bonita amistad entre ambos ya que ella también era una brillante estudiante de Odontología de la Universidad Mayor de San Marcos, luego llegó el amor y tres maravillosos hijos: Carlos Eduardo el primogénito excelente músico de profesión, Eric director y editor de cine y Freddie odontólogo y ortodoncista.

En el año 1970, el Dr. Freddie Williams fue llamado por el Dr. Roberto Beltrán fundador de nuestra Facultad a participar del primer grupo de internado en odontología en el Hospital del Rimac hoy llamado Hospital Nacional Cayetano Heredia, asume luego la condición de Jefe de internos. En 1971 forma parte del grupo de Pre docentes Fundadores de la Facultad de Estomatología de la Universidad Peruana Cayetano Heredia y es así que inicia otra de sus pasiones, la Docencia la cual viene desarrollando durante 47 años, siendo su carrera académica muy vasta desempeñándose como Secretario académico en 1990, Jefe de Departamento en 1993, obtiene el Grado de Doctor en Estomatología el año 1999, Vice - Decano de nuestra facultad entre los años 1999 - 2002 y Decano durante dos periodos de 2002 a 2005 y de 2005 a 2008 y Director de la Dirección de Posgrado del 2008 al 2011. Realizó sus estudios de Ortodoncia en la Universidad de Maryland en Estados Unidos en 1973, a pesar de que había sido aceptado en la Universidad de Harvard, pero le pareció el programa de Maryland muy innovador lo que le ayudó a tomar la decisión y optar por ella, esta capacitación la realizó con el apoyo de la fundación Kellog, recibiendo el título de Especialista en Ortodoncia en el año 1975, al respecto me manifiesta el Dr. Williams que fue una época un poco dura económicamente y para poder ayudarse tenía que trabajar de músico por las noches, técnico de laboratorio, luego como apoyo de la sección de ayudas audiovisuales en la docencia recibiendo el 
título de Especialista en preparación de material audiovisual en educación y aprovecha para estudiar fotografía en la escuela de Artes de Maryland recibiéndose como Especialista en Fotografía en el año de 1975, y entre los años 1975 a 76 se desempeña como Profesor y como ortodoncista en práctica privada en Estado Unidos. También fue Secretario fundador de la Asociación Latino americana de Ortodoncia- ALADO en 1978.

Es el pionero en el año 1990 de la enseñanza formal de Ortodoncia en el Perú al crear el Programa de Especialización en Ortodoncia.

En su gran trayectoria profesional fue, Presidente, Sociedad Peruana de Odontopediatría 1991 - 1993, Presidente, Sociedad Peruana de Ortodoncia 1999 - 2004, autor de 2 libros de la Especialidad de Ortodoncia, ganador del Premio Hipólito Unanue a la Mejor Investigación en Odontología 1996, Premio Grunenthal en Odontología: Primer Lugar Categoría Profesionales 1996, Premio Grunenthal en Odontología: Tercer Lugar Categoría Profesionales 1997, Condecoración Caduceo Odontológico del Colegio Odontológico del Perú 1999, Miembro Honorario de la Sociedad Peruana de Odontopediatría, ganador del Premio “Hipólito Unanue” a la Mejor Edición Científica 2001, Condecoración de la Orden Cayetano Heredia en Grado de Gran Oficial 2002, Presidente Consejo Consultivo de la Fundación Instituto Hipólito Unanue 2011 - 2013, Presidente del Distrito Peruano del International College of Dentists, ICD 2012 - 2015, Premio “Medalla de Oro Hipólito Unanue” a la trayectoria profesional 2015, Padrino y Epónimo de varias Promociones de Pre y Postgrado de la Facultad de Estomatología. Finalmente quiero manifestar que para nosotros sus exalumnos el representa un icono de la ORTODONCIA PERUANA que trataremos de emular y agradecerle por siempre.

Mg. Orlando Tuesta Da Cruz ${ }^{1, a}$ 